DOI 10.37882/2500-3682.2021.03.03

\title{
МЕТОДОЛОГИЧЕСКИЕ ОСНОВЫ ВЫЯВЛЕНИЯ ГУМАНИТАРНЫХ ИНФОРМАЦИОННО-ПСИХОЛОГИЧЕСКИХ УГРОЗ СТУДЕНТАМ ВУЗОВ РОССИЙСКОЙ ФЕДЕРАЦИИ
}

\section{METHODOLOGICAL FOUNDATIONS FOR IDENTIFYING HUMANITARIAN INFORMATION AND PSYCHOLOGICAL THREATS TO STUDENTS OF UNIVERSITIES OF THE RUSSIAN FEDERATION}

\section{A. Evsiouk}

Summary: This article examines the methodological foundations for identifying the main humanitarian information and psychological threats that modern students face, and attempts are made to introduce techniques in order to eliminate the negative impact of these threats.

Keywords: detection (identification), information and psychological threats, student, University, information security, methodological foundations.

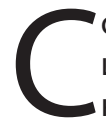
овременное общество в ретроспективном аспекте имеет достаточно высокий уровень безопасности, который объективно выше, чем в предыдущих поколениях. Однако, несмотря на все имеющиеся в данной области преимущества, человечество на современном этапе все равно нуждается в защищенности, так как внешние факторы оказывают сильное влияние на стабильность и безопасность нашего существования.

То, что вызывало опасение у наших предков, нас не беспокоит, однако нас беспокоят новые проблемы. Общество развивается, вместе с тем и развиваются технологии - системы и комплексы на новых физических принципах, новые технологии генерирования, обработки и передачи информации, элементы искусственного интеллекта несут в себе одновременно и преимущества, и негативные последствия. Кроме того, на региональном уровне происходят локальные войны и вооруженные конфликты, в мире систематически возникают новые угрозы развязывания ядерной войны (если и не столь явно, то даже перманентный рост государств, обладателей ядерного оружия, заставляет опасаться данной угрозы). Пандемия COVID-19 также вызывает беспокойство и несет в себе угрозы в разных сферах жизни.

В целом, на земле сегодня происходят события, подрывающие общественную безопасность, в числе которых можно выделить:

- глобализацию;

\author{
Евсюк Александр Владимирович \\ К.nсх.н., С.н.С., Военный университет Министерства \\ обороны Российской Федерации \\ avev2020@bk.ru
}

Аннотация: В данной статье рассматриваются методологические основы выявления основных информационно-психологических угр0з, с которыми сталкиваются современные студенты, а также предпринимаются попытки внедрения методик с целью устранения негативного влияния от данных угроз.

Ключевые слова: выявление, информационно-психологические угрозы, студент, вуз, информационная безопасность, методологические основы.

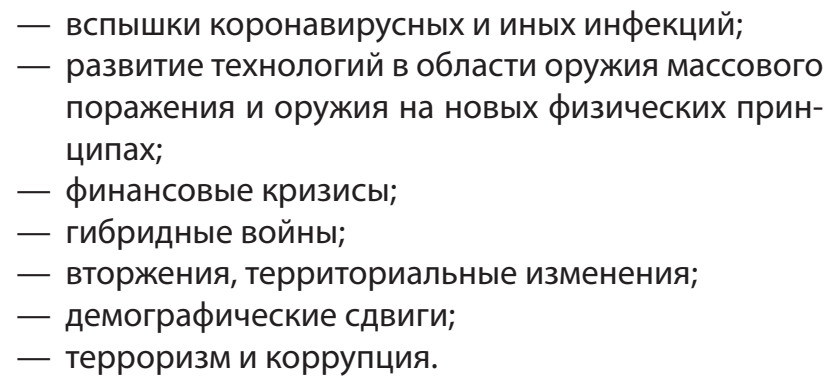

Bсе вышеназванные явления могут стать (и становятся) основой для гуманитарных информационно-психологических угроз человека. Личность в современном обществе подвергается большому количеству информационных угроз и является наиболее уязвимым субъектом в сфере обеспечения информационной безопасности [1, с. 55]. В том числе и потому, что о событиях и явлениях, происходящих вне пределов нашего физического присутствия, мы узнаем через посредничество различных источников информации. То есть в интерпретации, изложении.

Актуальность рассмотрения данной темы определяется тем, что современное общество характеризуется кризисными явлениями во многих сферах социальноэкономической и общественной жизни, что влечет за собой резкое изменение привычных стереотипов и моделей поведения, переоценку ценностей и идеалов, изменение мировоззренческих установок. Эта тенденция 
остро отражается на молодых людях, которые вовлечены в систему обучения: детях и подростках, студентах высших учебных заведений (далее - вуз). Кроме того, важность изучения этого вопроса, с учетом возможных негативных последствий, обусловлена необходимостью заблаговременного вскрытия воздействия недоброкачественной информации на сознание индивида, угрожающего его интеллектуальному, духовному, физическому развитию и благополучию. Актуальность исследования также заключается в необходимости более углубленного изучения методологических основ выявления гуманитарных информационно-психологических угроз студентам вузов Российской Федерации для эффективного практического использования в системе высшего профессионального образования.

Негативное воздействие на студентов социальных сетей и информационных ресурсов - вопрос, который недостаточно изучен на настоящий момент и требует детальной проработки. Этот вопрос важен и актуален тем, что его изучение поможет выработать методологические основы выявления подобного влияния, а также позволит проводить разнообразную разъяснительную работу, связанную с информационно-психологическими угрозами, которым подвергаются студенты.

В студенческой среде основными источниками информации до 90-х годов XX века являлись телевидение, радио, печатные СМИ, профильные СМИ, партнеры и коллеги по студенческому сообществу, научная и учебная литература, профессорско-преподавательский состав, администрация вуза. Начиная с последнего десятилетия XX века, стремительно нарастая в XXI, развивается тенденция отхода молодежи от использования традиционных источником информации. Альтернативой «классическим» сегодня выступают интернет-СМИ, блоги, социальные сети, чат-боты. При этом, интернет-медиа от создания информационной, идейно-воспитательной и просветительской «продукции» быстро перешли к генерированию особого высококонкурентного продукта - внимания аудитории. В стремлении «произвести» внимание молодежной аудитории каналы и издания открывают пользователям беспрепятственный доступ к разнообразному информационному контенту, воздействующему прежде всего на эмоциональную сферу, а точнее - на механизмы переживания.

B XXI веке, пожалуй, ни один студент (за редким исключением) не может представить мир без информационных технологий - интернет, гаджеты, различные информационные онлайн-источники и т.д. Даже учебный процесс в свете последних событий, связанных с пан- демией, во многих регионах был переведен на дистанционное онлайн-обучение и, возможно, такая практика продолжится во многих вузах и в ближайшей перспективе. Интернет заменил студентам книги, живое общение, досуг, обучение различным навыкам. С его помощью происходит социализация молодежи, она реализовывает свои способности, желания, навыки, познает окружающий мир, развивается и т.д. В проводимых в вузах психологических исследованиях ученые отмечают: уровень вовлеченности студентов российских колледжей и университетов в интернет-среду очень высокий; выделяются две ведущие цели использования ими интернета поиск полезной для учебы и интересной информации, а также общение в социальных сетях [2, с. 258].

Но, наряду с множеством положительных факторов, интернет несет в себе и негативное воздействие, формирующее угрозы информационно-психологической безопасности студентам [3, с. 78]. Баева И.А., Акиндинова И.А. и Ихер К.М. отмечая, что интернет пространство на современном этапе обладает как конструктивным, так и деструктивным потенциалом, указывает на недооценку молодыми людьми или даже отсутствует у них представлений о реальных угрозах психическому здоровью и позитивному развитию, которые существуют в сети интернет [2, с. 252, 258].

C учетом значений терминов «выявлять» ${ }^{1}$, «угроза»² и «информационно-психологическая безопасность» ${ }^{3}$, под выявлением гуманитарных информационно-психологических угроз студентам вузов Российской Федерации будем понимать обнаружение (вскрытие) любого потенциально возможного негативно-деструктивного воздействия информационных потоков, способных нанести вред психике молодежи, обучающейся в высших профессиональных учебных заведениях страны. При этом, выявление угроз выражается в систематическом анализе и контроле возможности появления реальных или потенциальных угроз и своевременных мерах по их предупреждению.

Основные источники информационно-психологических угроз традиционно включают в себя внешние и внутренние факторы. Учитывая, что внутренние факторы, определяющиеся индивидуальными особенностями психики личности, степенью ее восприимчивости к различным информационным воздействиям, возможностью критически анализировать и оценивать поступающие сведения не являются предметом нашего исследования, более подробно остановимся на внешних. Та часть информационной среды общества, которая искаженно представляет окружающий студента внешний

\footnotetext{
1 Выявлять - сделать явным, обнаружить, вскрыть [7].

2 Угроза - возможная опасность; запугивание, обещание причинить кому-нибудь вред, зло [8].

3 Информационно-психологическая безопасность личности - состояние защищенности психики от негативно-деструктивного воздействия информационных потоков [9].
} 
мир, информация, которая приводит к ложным выводам, и не дает возможности адекватно оценивать внешние предметы и явления, а также и себя самого, становится источником внешних угроз информационно-психологической безопасности. К ним относится информация, содержащая: гипертрофированное акцентирование внимания к чрезвычайным происшествиям, стихийным бедствиям, грядущим природным и техногенным катастрофам; апокалиптические взгляды, элементы нагнетания страха, паники, ажиотажа, недоверия, негативных ожиданий; ложные сведения о терактах, политическую, экономическую дезинформацию, фальсификацию исторических фактов. Основной целью распространения такой информации применительно к образовательной среде является искажение и разрушение мировоззрения студентов путем деидеологизации, формирования комплекса неполноценности, разрушения системы традиционных духовно-нравственных и исторических ценностей, подмены их иными идеалами и ориентациями. Кроме того, формируемая на основе источников чужеродного иностранного мейнстрима, такая информация призвана способствовать организации «бегства умов», разрушению системы отечественной науки, образования (в том числе высшего), необоснованному запрету на распространение новых знаний и технологий, разжиганию в молодежной среде разногласий по национальным, религиозным и иным признакам.

Феномен информационно-психологического воздействия является предметом целого ряда исследований, этой проблеме уделяли внимание специалисты различных научных направлений: социологии, психологии, философии, педагогики, политологии, культурологи.

Методология исследуемой проблемы традиционно опирается на основные принципы (историзм, универсализм, объективность, открытость и т.д.) и методы (общенаучные, частные и специальные).

В общем плане методологические функции по отношению к теории информационно-психологической безопасности выполняют:

- общая теория систем, решающая проблемы стабильности, сохранности, защищенности, безопасности в условиях воздействия на них деструктивных факторов;

- конфликтология, так как негативное воздействие сопряжено в социальной сфере с конфликтными ситуациями;

- общая теория управления, потому, что выявление (предотвращение) угроз информационно-психологической безопасности личности нереализуемо без конкретных информационно-управляющих воздействий.

В основе исследования проблемы выявления информационно-психологических угроз студентам вузов, но- сящей междисциплинарный характер, должны быть положены те учения, теории, концептуальные подходы, на основе которых развиваются теории психологической безопасности личности, психологической безопасности образовательной среды, информационной безопасности в целом.

Специальные методологические основы психологии, определяющие постулаты построения, методы, формы и способы научного познания рассматриваемой проблемы, включают ряд принципов:

- психологического детерминизма С.Л. Рубинштейна, согласно которому внешнее воздействие преломляется через психику человека и только после этого влияет на его реакции и поведение; внутреннее состояние в известной мере определяет те внешние воздействия, которые будут оказывать на него влияние;

- единства сознания и деятельности, в соответствии с которым психическое формируется в процессе деятельности и является субъективным выражением объективно протекающих процессов, в свою очередь регулирует эту деятельность и придает ей характер, направленный на самосохранение и развитие личности;

- системности, при котором в процессе индивидуального развития структуры психики проходят последовательные этапы усложнения, дифференциации и трансформации;

- развития в психологии, предполагающий исследование любого психического явления в непрерывном развитии, как процесс и результат деятельности.

Методологические основы исследования проблемы выявления гуманитарных информационно-психологических угроз должны быть направлены на формирование такой образовательной среды вуза, в которой бы были сведены к минимуму любые информационно-психологические угрозы студентам, поскольку в наше время формирование, развитие, самореализация человека происходит не только в реальном материальном мире, но и в информационной, виртуальной среде.

В настоящее время научное сообщество, безусловно, приходит к осознанию данной проблемы, но говорить о более или менее сформировавшихся путях ее решения пока еще преждевременно. Поэтому очень важно в условиях высших учебных заведений разобраться в психологических особенностях восприятия молодежью информации в современном мире, а также разработать эффективные инструменты по выявлению информационно-психологических угроз.

Вузы, помимо просветительской и образовательной, имеют ряд иных функций, среди которых присутствуют нравственные, культурные и духовные аспекты, а с не- 
давних пор и воспитательные [4]. Преподавателям очень важно уметь разбираться в психологических особенностях молодежи, а также понимать, что образовательный процесс в университете (институте) составляет важную часть жизни студентов. Высшее профессиональное учебное заведение - это место, где они взрослеют, происходит становление их личностей, где появляются моральные и жизненные устои, формируется мировоззрение. В этой связи важная и ответственная роль должна быть отведена гуманитарным наукам, в частности, философии, психологии, в рамках которых можно было бы разработать механизмы выявления информационнопсихологических угроз.

Важно также отметить, что сама по себе информация угрозы не несет, однако она может превратиться в таковую, если у студента наблюдается снижение осознанности происходящего путем активизации его чувственно-эмоциональных реакций во вред рационально-осознанным. Другими словами, если психика и мировоззрение студента еще находится в стадии формирования, что вполне естественно для времени обучения в университете, то информационные угрозы могут нанести вред студенту, а также эволюционировать, что может повлечь за собой деформацию личности и даже стать началом развития девиантного и деструктивного поведения.

Дмитриева Л.Г., Хамзина Д.В. в своих исследованиях отмечают, что "у студентов, которые являются активными пользователями социальных сетей, проявление черствости более выражено, чем у студентов, которые реже пользуются социальными сетями. Студенты - неактивные пользователи социальных сетей характеризуются большей чуткостью и более глубоким пониманием других людей» [5, с. 184]. Информационные и новостные ресурсы на сегодняшний день оказывают большое воздействие на студентов, вводя их в так называемую псевдореальность. В этой связи очень важно оберегать информационную и психологическую безопасность студентов.

Ведущим национальным интересом в области информационно-психологической безопасности студентов ВУЗов должно стать обеспечение способности системы отечественного образования функционировать в режиме расширенного воспроизводства обучающей среды с соблюдением принципа максимальной защищенности от внешнего негативного информационного воздействия. Вместе с тем, данный тезис не предусматривает существования научной и образовательной среды страны в условиях автономии (что фактически невозможно в современной мировом информационном пространстве), но ориентирует государство, как регулятора общественных отношений в сфере высшего профессионального образования (или отдельный вуз) на максимально эффективное использование своего ресурсного потенциа- ла. При этом в каждом конкретном случае содержание потенциала является различным, а следовательно, меры и задачи формализации информационно-психологической безопасности необходимо осуществлять применительно к конкретному объекту исследования.

Теперь рассмотрим методы, которые помогают своевременно выявить информационно-психологические угрозы, с которыми ежедневно сталкиваются студенты. Среди них мы выделяем следующие:

1. Эффективной методикой выявления информационно-психологических угроз студентам может стать контент-анализ информационных источников. Это метод выявления и оценки специфических характеристик текстов и других носителей информации, в которых соответственно целям исследования выделяются определенные смысловые единицы содержания и формы информации. В ходе его проведения определяется исследовательская выборка источников данных, формируется список измеряемых категорий, формулируются единицы кодирования, проводится анализ собранных данных, осуществляется представление результатов. Современную концептуальную основу контент-анализа предложил К. Криппендорфф.

2. Систематический метод. Систематический метод выявления информационно-психологических угроз студентам вузов Российской Федерации предполагает определенную, строго последовательную систему работы, построенную по конкретному плану. Он подразумевает непрерывный процесс, направленный на выявление и определение угроз на всех этапах образовательного процесса, последующую классификацию источника угрозы и оценку возможного ущерба в случае реализации угрозы.

Важным направлением такого подхода является активная научно-исследовательская работы в вузе по систематическому анализу и контролю возможности появления реальных или потенциальных угроз и выработке своевременных мер по их предупреждению.

3. Метод идентификации возможных источников угроз. Идентификация предполагает подтверждение (или опровержение) факта достоверности информации (ее источника). Процесс выявления гуманитарных информационно-психологических угроз студентам вузов Российской Федерации предполагает систематическое установление тождественности выявленного неизвестного объекта известному (сходному) на основании совпадения признаков, то есть распознание источников угроз, оценку возможности и, исходя из этого, выявление актуальных угроз.

4. Метод оценки вероятности реализации угроз. Существует возможность оценки степени вероятности 
реализации анализируемых информационно-психологических угроз студентам вузов Российской Федерации с соразмерным потенциалом и оценкой причиняемого ущерба.

5. Регулирование информационных источников. Данный подход предусматривает, что студентам необходимо отказываться от тех информационных ресурсов, достоверность данных которых не подтверждена. К примеру, это может быть информационная среда Даркнет (от англ. DarkNet - «Скрытая сеть», «Тёмная сеть», «Теневая сеть», «Тёмный веб»). На уровне образовательной организации необходимо создание кафедры медиапсихологии [6, с. 39], реализующей подготовку студентов к избирательной обработке сетевой информации.

6. Доведение информации до студентов об информационно-психологических угрозах - просветительская функция. Данная методика призвана способствовать обеспечению информационной безопасности студентов, а также сведению к минимуму негативного влияния на них информации, несущей угрозы их психике. Сюда также можно отнести ознакомление обучающихся с правилами самостоятельного поиска информации, который необходимо осуществлять с использованием нескольких достоверных (официальных) источников, при этом тщательно сравнивать и анализировать информацию, не опираться в суждениях и умозаключениях на то, что предоставлено в одном сомнительном источнике. На базе психологических кафедр данную методику можно внедрить путем создания канала на YouTube или подкаста, который содержал бы в себе качественный и достоверный контент, а также информировал бы об информационно-психологических угрозах, с которыми может столкнуться студент.

7. Доведение до студентов важной информации в рамках ежедневных занятий в вузе. Такая методика может включать в себя различные формы предоставления преподавателями важной и актуальной информации, к примеру, социального характера. Подход может быть особенно актуальным в дни празднования важных исторических событий страны, проведения общественно значимых мероприятий в стране, регионе или вузе для популяризации духовных и культурных ценностей, морально-этических норм, значимых традиций.

8. Поиск эффективных механизмов, направленных на защиту студентов от информационно-психологических угроз. Данные механизмы должны учитывать и содержать в себе приемы и средства, которые поддерживали бы благоприятный морально-психологический климат в студенческих группах и потоках, а также формировали у студентов понимание того, что именно они в ближайшем будущем сформируют интеллектуальную элиту общества, от них будет зависеть вектор развития всего государства, в связи с чем им необходимо заботиться о своем психическом здоровье и ограждать себя от потенциально опасных информационных ресурсов.

9. Развитие у студентов навыков устойчивости к информационно-психологических угрозам. Этот комплекс действий направлен на формирование у студентов опыта безопасного информационно-коммуникационного взаимодействия для формирования индивидуального психологического механизма самозащиты. Кроме того, помимо вуза, психологически благоприятный климат должен быть сформирован в семейном кругу студентов, в окружении их друзей, знакомых и т.д.

В целях анализа состояния образовательной среды вуза на соответствие ее критериям информационнопсихологической безопасности показателями для измерения могут стать комфортность и психологическая безопасность. К характеристикам, выявляемым опытным путем, могут быть причислены отношение к информационно-образовательной среде в целом (референтность), удовлетворенность ее базовыми показателями по оценкам студентов вузов и профессорско-преподавательского состава. Кроме того, при анализе образовательной среды на предмет ее информационно-психологической безопасности могут быть использованы также оценки параметров ценностно-смысловой сферы студентов, готовности к активному образовательному процессу и научным исследованиям, данные экспертным сообществом преподавателей, а также насыщенности образовательной среды вуза рисками, замеряемые у обучающейся молодежи.

Методика выявления информационно-психологических угроз студентам может включать в себя ряд мер, среди которых можно выделить:

- правовое обеспечение - специальные законы и иные нормативные акты, правила, процедуры и меры (в том числе ведомственные и вузовские), направленные на обеспечение безопасности информационной среды личности на законодательно-правовой основе, на реализацию единой государственной политики в области защиты от информационных материалов, наносящих вред здоровью и психике;

- технические и программные мероприятия, предусматривающие использование различных видов аппаратных и программных средств для предотвращения материального и морального вреда обучающемуся (средства защиты сетевых данных, собственная электронная образовательная среда вуза, программы родительского контроля);

- воспитательная деятельность - формирование у подрастающего поколения культуры психологической безопасности, ответственности за действия, совершаемые в информационном пространстве, воспитание и укрепление традиционных духовно-нравственных ценностей, патрио- 
тизма, готовности преподавателей и родителей к принятию личностной позиции и уважению их самостоятельности;

- организационные меры - регулирование информационной деятельности обучающихся, контроль за использованием сетевых сервисов и сообществ, мониторинг сетевой активности, что исключает или уменьшает вред для персональной информационной среды молодого гражданина страны;

- морально-этические меры, включающие в себя соблюдение студентами норм и правил поведения, а также сетевой культуры и этики, которые формируются с распространением информационных технологий в современном обществе.

Понимание объективного существования угроз информационно-психологических воздействий обуславливает необходимость внимательного рассмотрения проблем обеспечения защиты индивидуального и группового сознания членов студенческого сообщества вузов Российской Федерации от подобных воздействий, имеющих негативный (деструктивный) характер. Постоянно нарастающая в информационной среде вероятность деструктивного информационно-психологического воздействия на молодую формирующуюся личность обучающегося в системе высшего профессионального образования с целью деформации его психики может в уже в ближайшей перспективе привести к непоправимым последствиям для страны и ее гражданского общества, если заинтересованные институты государственной власти во взаимодействии с научно-педагогическим сообществом не примут заблаговременных мер по предупреждению и нейтрализации такого воздействия. С целью выявления и минимизации гуманитарных информационно-психологической угроз безопасности студентам вузов Российской Федерации необходимо на государственном уровне продолжить работу по совершенствованию нормативно-правовой базы по защите личности и общества от негативных информационнопсихологических воздействий, а в системе высшего профессионального образования разработать и приступить к реализации программ совершенствования работы по формированию безопасной информационно-образовательной среды с учетом специфики каждой учебного заведения.

В завершении нашего исследования представляется целесообразным сформулировать ряд выводов.

1. Ведущим национальным интересом в области информационно-психологической безопасности студентов ВУЗов должно стать обеспечение способности системы отечественного образования функционировать в режиме расширенного воспроизводства обучающей среды с соблюдением принципа максимальной защищенности от внешнего негативного информационного воздействия. При этом, данный тезис не предусматривает существования научной и образовательной среды страны в условиях автаркии (что фактически невозможно в современной мировом информационном пространстве), но ориентирует государство, как регулятора общественных отношений в сфере высшего профессионального образования (или отдельный вуз) на максимально эффективное использование своего ресурсного потенциала.

2. Под выявлением гуманитарных информационно-психологических угроз студентам вузов Российской Федерации будем понимать обнаружение (вскрытие) любых потенциально возможных негативно-деструктивных воздействий информационных потоков, способных нанести вред психике молодежи, обучающейся в высших профессиональных учебных заведениях страны. При этом, выявление угроз должно выражаться в систематическом анализе и контроле возможности появления реальных или потенциальных угроз и своевременных мерах по их предупреждению.

3. Методологические основы выявления гуманитарных информационно-психологических угроз должны способствовать планомерной и эффективной работе администрации и профессорскопреподавательского состава вуза по сведению к минимуму любых информационно-психологических угроз обучающимся студентам, созданию комфортной и психологически безопасной информационно-образовательной среды вуза.

4. В основе исследования проблемы выявления информационно-психологических угроз студентам вузов, носящей междисциплинарный характер, должны быть положены те учения, теории, концептуальные подходы, на основе которых развиваются теории психологической безопасности личности, психологической безопасности образовательной среды, информационной безопасности в целом.

5. К основным методам выявления гуманитарных информационно-психологических угроз студентам вузов Российской Федерации можно отнести метод контент-анализа информационных источников, систематический метод, метод идентификации возможных источников угроз, метод оценки вероятности реализации угроз.

6. Общим принципом выявления информационнопсихологических угроз студентам вузов Российской Федерации должна быть оценка возможности анализируемых информационных ресурсов и содержащейся в ней информации стать источником потенциальной опасности их психическому здоровью. 


\section{ЛИТЕРАТУРА}

1. Логинова Т.Д. Механизм обеспечения права личности на информационную безопасность // Вестник Восточно-Сибирского института МВД России. 2018. № 36 (86). С. 55-61.

2. Баева И.А., Акиндинова И.А., Ихер К.М. Осознание психологических угроз в интернет-среде студентами вуза и колледжа // Сборник статей по материалам Международной научно-практической конференции, посвящается 75-летию Гуманитарно-педагогической академии / Под редакцией Коврова В.В. 2019. С. 252-259.

3. Жихарева Л.В. Мотивационная структура медийных предпочтений современной молодежи // Научный результат. Педагогика и психология образования. 2019. Т. 5. № 4. С. 78-86.

4. Федеральный закон от 31 июля 2020 г. № 304-Ф3 «0 внесении изменений в Федеральный закон «06 образовании в Российской Федерации» по вопросам воспитания обучающихся» // Сайт «Гарант». URL: https://www.garant.ru/products/ipo/prime/doc/74351950/.

5. Дмитриева Л.Г., Хамзина Д.В. Особенности проявления эмпатии у студентов - пользователей социальных сетей // Вестник Московского государственного лингвистического университета. Образование и педагогические науки. 2020. № 1 (834). URL: https://cyberleninka.ru/article/n/osobennostiproyavleniyaempatii-u-studentov-polzovateley-sotsialnyh-setey.

6. Евсюк А.В. Методологические основы противодействия гуманитарным информационно-психологическим угрозам студентам вузов Российской Федерации // Современная наука: актуальные проблемы теории и практики. Серия: Познание. 2020. № 8. С. 38-43.

7. Ожегов С.И., Шведова Н.Ю. Выявление // Толковый словарь русского языка. 4-е изд. М.: 000 «А Темп», 2006. 944 с.

8. Ожегов С.И., Шведова Н.Ю. Угроза // Толковый словарь русского языка. 4-е изд. М.: 000 «А Темп», 2006.944 с.

9. Власова В.Н. Информационно-психологическая безопасность личности в информационном обществе // Актуальные проблемы научно-методического обеспечения процесса безопасности жизнедеятельности школьников и студентов в сфере образования. Материалы Всероссийской научно-практической конференции. Ростов н/Д., 2019. С. 18-21.

(c) Евсюк Александр Владимирович (avev2020@bk.ru).

Журнал «Современная наука: актуальные проблемы теории и практики»

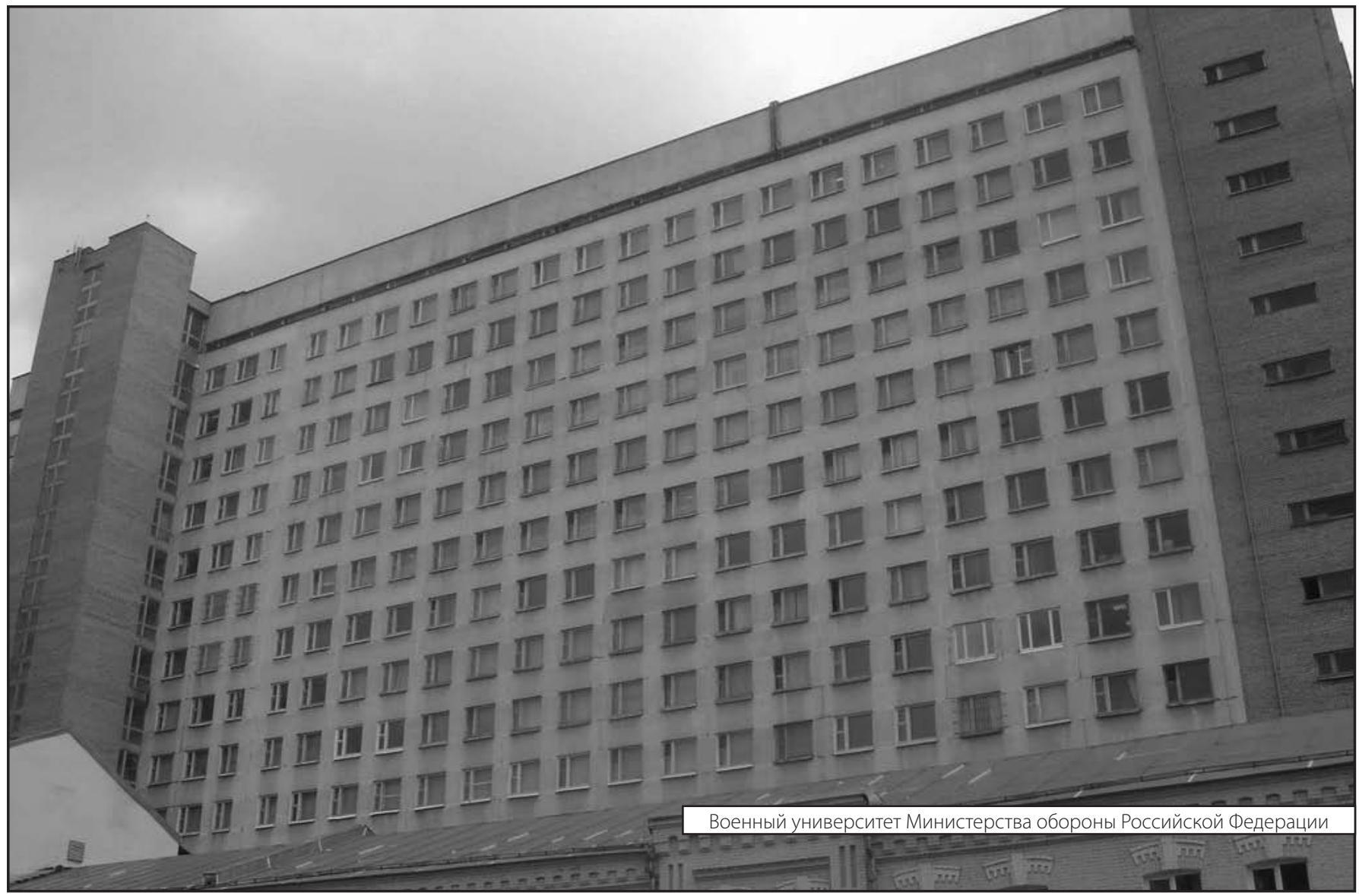

